\title{
The Empirical Analysis of Disease Burden and Wealth Creation in Nigeria
}

\author{
Isuwa Festus Dading*, Sowemimo Joy Eseosa, Mokobia Ngozi Alison, Mercy Ada Anyiwe \\ Department of Economics, University of Benin, Benin City, Nigeria \\ E-mail: festusdading@yahoo.com, isuwa.dading@uniben.edu
}

Received: 7 December 2020; Revised: 20 February 2021; Accepted: 29 March 2021

\begin{abstract}
The study investigates the impact of disease burden on wealth creation in Nigeria using annual time series data ranging from 2006-2018. The different levels of integration of the data warrant the use of Autoregressive Distributed Lag (ARDL) model as methodology for the analysis. The theoretical framework was based on the Disability Life Years (DALY) of Murray (1996) which says that the burden of disease is arrived at by the number of years a person loses as a result of dying early due to ailments and the number of years of life a person lives with disability caused by the disease. The long run empirical analysis revealed that wealth creation has impact on disease burden in Nigeria. This conversely infers that as the source of livelihood increase, the disease burden on the population is reduced because people will have income to attract health consideration which invariably will reduce the chances of suffering from diseases. The life expectancy at birth has a more significant impact on disease burden than population and even wealth creation. It is therefore recommended that measures that lead to wealth creation should be harnessed as this will greatly reduce the burden of diseases in Nigeria which will invariably increase life expectancy at birth.
\end{abstract}

Keywords: disease burden, wealth creation, DALY, ARDL model

JEL Codes: B41, C20, 112, 115

\section{Introduction}

The burden of disease a county bears can greatly affect every aspect of its endeavours both economically, socially, morally and otherwise. Sub Saharan Africa seems to suffer the most from disease burden in comparison to other regions of the world. The Burden of Disease measure was developed in the late 90s by the World Bank, World Health Organization (WHO) and the Harvard School of Public Health and it refers to death or the loss of health arising from diseases, injuries and risk factors for every region of the world (WHO, 2008). The report further declares that the burden of disease is arrived at by the number of years a person loses as a result of dying early due to ailments and the number of years of life a person lives with disability caused by the disease. When the two are added together, a single figure is arrived at called Disability Adjusted Life Years (DALY). Murray (1996) posits that DALY is "a health gap measure that extends the concept of potential years of life lost due to premature death to include equivalent years of healthy life lost by virtue of individuals being in states of poor health or disability". Information on the risk factor burden serves as a

Copyright (C2021 Isuwa Festus Dading, et al.

DOI: https://doi.org/10.37256/redr.212021740

This is an open-access article distributed under a CC BY license

(Creative Commons Attribution 4.0 International License)

https://creativecommons.org/licenses/by/4.0/ 
vital input for resource allocation for research and development. Also, lessons from Global Burden of Disease report are critical and fundamental for development of coherent health policies. Hence, estimates of the burden of disease become necessary to formulate and put into practice research and development priorities for an overall effective development (Lopez et al., 2006).

Globally, heart disease is the main cause of demise for adults within the aged range of 60 and above and it comes second (after HIV) for those aged 15-59 (WHO, 2008). This shows that there is one death in every three of which the GBD study conditions Group I (communicable diseases, maternal and prenatal conditions, and nutritional deficiencies) causes. In underdeveloped and developing countries, the aphorism "Group II causes" (non-communicable diseases) are capable of causing more than 50 percent of deaths in adults ages 15 to 59 in all regions except South Asia and SubSaharan Africa, where Group I causes, including HIV/AIDS, continue to be responsible for one-third and two-thirds of deaths, respectively (Lopez et al., 2006; WHO, 2020). It is not surprising that Africa as a whole remains the furthest and the most left behind in the world's regions when it comes to health improvements and prolonged existence.

It is against this backdrop that the study seeks to determine how disease burden impact wealth creation in Nigeria. To achieve this objective, it is pertinent to address the following questions: 1. Does disease burden affect wealth creation in Nigeria? 2. Does poverty influence disease burden in Nigeria? 3. Is there a link between disease burden, life expectancy at birth and population growth rate in Nigeria? The rest part of this paper is structured as follows: Section 2 contains a review of relevant literature while section 3 provides the methodology adopted; section 4 presents the results and discussion and section 5 concludes the paper after recommendation.

\section{Literature review}

In the year 2005-2010, the life expectancy at birth in most developed regions of the world was estimated to be 77 years, this was found to be 4 years lesser in Latin America and the Caribbean (73 years), 7 years shorter in Asia (70 years) but show a high disparity of 21 years in Africa (56 years), and nearly 24 years shorter in sub-Saharan Africa (SSA) in 53 years (Defo, 2014). The great differences are pointers of variation in the demographic, epidemiological and economic changes that have taken place in various regions around the world. The increases in longevity have been accompanied by a historic shift in the cause-specific mortality risks in human populations.

Over the years, there seems to be a correlation between disease burden and education. One of such studies is by Hansen and Strulik (2015) which in their empirical studies on the effects of the cardiovascular revolution on the development of adult life expectancy and higher education. The study applied an instrumental-variable approach to spot the reduced-form brunt of adult life expectancy on advanced education. The findings suggest that the cardiovascular revolution caused an increase in life expectancy of 1.5 years and an increase in education enrollment of 9 percentage points, i.e. 52 percent of the observed enlargement between 1960 and 2000.

The World Health Survey conducted by World Health Organization brought revised disability weights which was developed in 2003 and are based on health state valuations from representative samples population in over 70 countries. This is in line with the GBD 2000 project which adopted a move toward the health position valuation, with a standard health condition description based on eight core domains of health which affects; mobility, self care, pain and discomfort, cognition, interpersonal activities, vision, sleep and energy, affect. Going by this, Murray and Lopez (1996) survey showed that AIDS has mean disability weight of 0.50 for both treated and untreated forms; followed by episodes of lower respiratory tract infection of 0.28 for the treated and the untreated forms. The mean disability weight for Malaria cases was 0.20 , for cancers at the terminal stage was 0.81 and infertility was 0.18 . The least among the cases was Asthma, with the mean disability of 0.10 for the untreated cases and 0.06 for the treated.

Health is comparable to a normal commodity of which the economic theory states that higher income leads to an increased demand for health, but the health status of a person also affects his or her income and earnings through different channels (Grossman, 1972). This can further be understood to mean that health is not just demanded for its own sake but is derived for what it can help the individual do. According to Van Zon and Muysken (2001) the analysis of the connection between economic growth, health and longevity in the light of macroeconomic growth models is integral to the micro foundations of health economics. In a similar research, Morand (2002) and Omran (1971; 1982) develop a theoretical framework that better explains the historical relationship between income and a particular measure of health and longevity by incorporating findings from the area of health economics into an endogenous growth model which 
was discovered that, demographers and economists have documented the tremendous gains in longevity and income attributing to the period of the 19th Century and even up to the present in many countries and the clear divergence in the main causes of mortality between these periods brought about the use of the term "Epidemiological Transition" by Epidemiologists to refer to the spectacular changes between the two periods.

The GBD in 2010, as part of its policy to measure the change in the expectation of the burden of disease based on how changes in population size and the age of the world populace affects the burden of diseases across the globe. The effects of population growth alone would increase the number of DALYs from all causes, but because population growth keeps rising in sub-Saharan Africa, it invariably would raise DALYs caused by communicable, maternal, neonatal, and nutritional diseases by $47.6 \%$, those caused by non-contagious diseases by $27.8 \%$, and those caused by injuries by $32.6 \%$. According to Murray, D.Phil and Lopez (2013), population growth and aging which drives demographic change is one of the input factors responsible for the expansions in the burden of non-infectious diseases.

\subsection{Theoretical literature}

Knowing whether one is healthy or sick is a personal thing and hence, individualistic. It may be difficult to determine the healthy nature or unhealthy nature of a given population without using mortality-based displays. It is based on this backdrop that the study seek to use DALY. The DALY was developed in 1990 by the World Health Organizations (WHO, 1990) as a way of weighing the disease burden and its disability on the populace. DALY is superior to Quality Adjustment Life Years (QUALY) even though both measures summarize population health used in burden of disease estimates. DALY and QUALY however differ in the sense that DALY weight the distinction or breach existing between the present health conditions of a population with an ideal situation where everyone is expected to reach the given standard life expectancy in perfect state. While QUALY is used to determine the extent to which clinical intervention will bring about good quality life. In other words, the DALY talks about the current condition of one's health status where one is expected to reach a given life expectancy but QUALY makes use of intervention to attain a given life expectancy years. QUALY use utility measures that ranges between 0 and 1 . Where 1 is a state of perfect health condition and zero is a state of death. This is generated through the information gotten from the respondents through personal interviews or questions given to the respondents or their relatives.

According to Lajoie (2015) Disability Adjusted Life Years calculate the heavy weight or burden of disease which can be given as the collective number of years lost due to infirmity, disability or early death. DALY is calculated by summing up the Years Lived with Disability (YLD) and Years of Life Lost (YLL).

$$
\text { Symbolically, } D A L Y=Y L D+Y L L \text {. }
$$

This is built on the assumptions that time is the most effective measure of disability or diseases burden.

Where, YLL is the number of mortalities recorded multiplied by life expectancy standard in years at the age of death.

And the YLD is arrived at when we multiply the number of disability cases by the incidence cases by the average interval of the disease/disability and weighted representations of disability called the disability weight. That is

$$
Y L D=I \times D W \times L
$$

Where

$$
\begin{aligned}
& Y L D=\text { Years Lived with Disability, } \\
& I=\text { Incidence cases of the disease, } \\
& D W=\text { Disability Weight, } \\
& L=\text { life lived which is the duration until death. }
\end{aligned}
$$




\section{Empirical model}

The theory of DALY established a link between diseases and the health of the population. Given that diseases impact negatively on the health status of humans as the incidence of any disease or infection left untreated would cause an individual's health to degenerate which could lead to demise (Dading \& kanwanye, 2019). Consequently, the level of health one enjoys comes as a result of the survival or otherwise from an infectious disease. In relation to the current study, health outcome such as maternal mortality is determined by the presence of an infectious disease like malaria, HIV/AIDS, Diabetes, etc which are common among the population of Nigeria. This theory serves as a fundamental framework on which our model is formed. The disease burden was grossly captured by malaria incidences since malaria constitutes roughly 60 percent of outpatient appointments and 30 percent of admissions. It also contributes up to 11 percent of maternal death, 25 percent of infant mortality, and 30 percent of under-5 mortality (The Nigeria Malaria Indicator Survey, 2015; Maigemu \& Hassan 2015).

It is against this backdrop that the study objective was built mainly to look at the impact of disease burden on wealth creation in Nigeria. Other control variables include; population, life expectancy at birth, trade in services and personal remittance received.

Following Nwanosike et al. (2015) and Mojekwu and Ibekwe (2012), the empirical model for this study with some modification is thus:

$$
D B=f(P O P, L E B, P R R, T I S, E D B)
$$

Equation (1) can be written in Econometric form as:

$$
D B_{t}=a_{0}+a_{1} P O P_{t}+a_{2} L E B+a_{3} P R R+a_{4} T I S_{t}+a_{5} E D B+U_{t}
$$

Where

$$
\begin{aligned}
& D B=\text { Disease Burden, } \\
& P O P=\text { Population, } \\
& L E B=\text { Life Expectancy at Birth, } \\
& T I S=\text { Trade in services, } \\
& P R R=\text { Personal Remittance Received, } \\
& E D B=\text { Ease of Doing Business, } \\
& U=\text { Error Term, } \\
& t=\text { Time Period, }
\end{aligned}
$$

$a_{i} s$ are the respective parameters to be estimated with $a_{0}$ being the intercept and $a_{1}-a_{5}$ are the slopes. The apriori expectations require that $a_{1}$ be greater than zero and $a_{2}$ to $a_{5}$ are expected to be less than zero. For $a_{1}$ to be greater than zero, this means that as the population increases, the disease burden will also increase in the same manner. Which means increase in population will have a positive impact on disease burden. In the same vein, as $a_{2}$ to $a_{5}$ increases, the disease burden will reduce, all things being equal. This can clearly be seen that as Life Expectancy at Birth, Trade in services, Personal Remittance Received and Ease of Doing Business increase of these variables have the tendency of reducing the burden of diseases, all things being equal. 


$$
\begin{aligned}
& D B_{t}=\sum_{i=1}^{p} D B_{t-i}+\sum_{i=1}^{p} T I S_{t-i}+u_{1 t} \\
& T I S_{t}=\sum_{i=1}^{p} D B_{t-i}+\sum_{i=1}^{p} T I S_{t-i}+u_{2 t}
\end{aligned}
$$

The Equations 3 and 4 are stated in a Granger causality framework to ascertain the direction of causation between disease burden and wealth creation in Nigeria. The lag length is indicated by rho, $\rho$.

\subsection{Estimation techniques}

In this study, efforts were made to empirically find the impact of disease burden on wealth creation in Nigeria. The ECM and Granger causality models specified in the previous section are estimated using the Ordinary Least Squares (OLS) regression approach. The OLS approach is adopted for its best linear unbiased and efficient properties when compared with other linear unbiased estimators. The stationary properties of the variables are, however, conducted using the Augmented Dickey-Fuller (1979) unit root test as well as the Engle and Granger (1987) cointegration test as preestimation before the estimations proper. The Autoregressive Distributed Lag (ARDL) model was adopted and taken for post-estimation analyses because some variables are not integrated of the same order. Some were integrated at order one while some at levels which warrant the need for an ARDL model to be performed to evaluate the validity of the results for policy relevance.

Data for this work were sourced from World Bank's World Development Indicators (WDI, 2019). The study period ranging from 2006 to 2018 was chosen based on availability of data for these variables. Annual total number of malaria cases in the country was used to capture disease burden since it constitutes roughly of about 60 percent of outpatient appointments and 30 percent of admissions.

\section{Results and discussion}

Table 1 presents the unit root results at levels. It shows that all the variables had Augmented Dickey-Fuller (ADF) statistics less than their corresponding 5 percent critical values, in absolute terms. We do not reject the null hypothesis of unit root. Thus, the variables are non-stationary at levels except for population and trade in services. It is common knowledge that most time series variables are not always stationary at levels. Granger and Newbold (1974); Iyoha (2004) in extant literature show the dangers of running a regression on non-stationary data of which we know would lead to a spurious and not meaningful regression result which may not be good for policy and therefore, the need to difference the variables to make it stationary for policy viability.

Table 1. Result of unit root test at levels

\begin{tabular}{cccc}
\hline Variables & ADF statistic & $5 \%$ Critical Value & Order of Integration \\
\hline DB & $-2,395081$ & -2.976263 & $\mathrm{I}(1)$ \\
LEB & -0.233072 & -3.012363 & $\mathrm{I}(1)$ \\
POP & -4.554786 & -3.004861 & $\mathrm{I}(1)$ \\
PRR & -2.076172 & -2.971853 & $\mathrm{I}(1)$ \\
EDB & -2.098879 & -3.144920 & $\mathrm{I}(1)$ \\
TIS & -3.212123 & -2.971853 & $\mathrm{I}(1)$ \\
\hline
\end{tabular}

Source: Authors' Computation (2020) using Eviews 9 
After the first difference and testing for the unit root of the variables, all the ADF statistics is now greater than their corresponding 5 percent critical values in absolute terms (Table 2). This suggests that all the variables were stationary after first difference. Hence, all the variables are integrated of order one, I (1).

Table 2. Result of unit root test at first difference

\begin{tabular}{cccc}
\hline Variables & ADF stat & $5 \%$ Critical Value & Order of Integration \\
\hline DDB & -3.066303 & -2.981038 & $\mathrm{I}(0)$ \\
DLEB & -3.477051 & -3.020686 & $\mathrm{I}(0)$ \\
DEDB & -3.748150 & -3.212696 & $\mathrm{I}(0)$ \\
DPRR & -5.399231 & -2.976263 & $\mathrm{I}(0)$ \\
\hline
\end{tabular}

$\mathrm{D}$ is the difference factor showing the order of integration. Which means that the variables are difference once, meaning that the variable is stationary after first difference. LEB is abbreviation for Life Expectancy at Birth, EDB is for Ease of Doing Business and PRR is the Percentage of Remittance Received.

Source: Authors' Computation (2020) using Eviews 9

The Bound test conducted shows that there is no cointegration between the variables as such there is therefore, no need for the short run analysis Error Correction Mechanism (ECM) as this is not necessary.

Table 3. ARDL result of the impact of disease burden on wealth creation in Nigeria

\begin{tabular}{|c|c|c|c|c|}
\hline Variables & Coefficients & Std. Error & t-statistics & Prob. \\
\hline $\mathrm{C}$ & -0.321848 & 1.861049 & -0.172939 & 0.8645 \\
\hline $\operatorname{LOGDB}(-1)$ & 0.248945 & 0.169087 & 1.472288 & 0.1573 \\
\hline LOGPOP & 2.598577 & 0.934343 & 2.781182 & 0.0119 \\
\hline LOGLEB & 39.49527 & 15.62399 & 2.527861 & 0.0205 \\
\hline LOGLEB $(-1)$ & -51.93016 & 18.77740 & -2.765568 & 0.0123 \\
\hline LOGPRR & -0.002043 & 0.066610 & -0.030673 & 0.9759 \\
\hline LOGTIS & -0.061223 & 0.085102 & -0.719409 & 0.4806 \\
\hline LOGTIS (-1) & 0.216906 & 0.078972 & 2.746632 & 0.0128 \\
\hline \multicolumn{5}{|c|}{ R-squared 0.990011} \\
\hline \multicolumn{5}{|c|}{ Adjusted R-squared 0.984330} \\
\hline \multicolumn{5}{|c|}{ F-statistic $269.0011^{* * *}$} \\
\hline \multicolumn{5}{|c|}{ Prob. (F-statistic) 0.000000} \\
\hline \multicolumn{5}{|c|}{ Durbin-Watson stat 1.997936} \\
\hline
\end{tabular}

Note: ***,** and *indicate significance at $1 \%, 5 \%$ and $10 \%$ level respectively. $\mathrm{C}$ is the constant variables which is automatically generated by the Econometric Views (E-Views) softwares. Log of variables means that all the varibles are expressed in percentages and so the interpretations of the variables must be made in percentages.

Source: Authors' Computation (2020) using E-Views 9

The estimated results indicate that population, life expectancy at birth and wealth creation significantly affects disease burden in Nigeria. The impact of population on disease burden shows that one percent increase in population, the disease burden will increase to about 3 percent which is statistically significant at $5 \%$. Wealth creation has a 
significant relationship on the disease burden in Nigeria. Our apriori expectation requires it to be negative which is appropriate with the empirical evidence which shows that increase in wealth creation has the ability of reducing disease burden. This means that as source of livelihood increase, the disease burden on the population is reduced because people will have income to attract medical attention which invariably will reduce the chances of suffering from diseases. The life expectancy at birth has more impact on disease burden than population and even wealth creation. The empirical evidence shows that a percentage increase in life expectancy at birth, the disease burden will increase to about $39.5 \%$. This is not in conformity with the apriori expectation. The life expectancy at birth is expected to reduce the disease burden but because the life expectancy in Nigeria is too low based on the empirical evidence, instead of reducing the disease burden, it increases it.

From Table 3, the coefficient of determination and its adjusted counterpart show that the model has a high goodness of fit and predictive ability. Specifically, the coefficient of determination (R-squared) of 0.9941 indicates that about $99 \%$ of the systematic variation in the disease burden is accounted for by the independent variables. Even after accounting for the degrees of freedom, the model is still having high predictive ability of $98 \%$. This shows that the model was able to capture about $98 \%$ of the relationships that exist between the dependent variable and explanatory variables. The F-statistic (269.0011) was significant at the 1 percent level implying that a significant relation exists between disease burden and the independent variables put together. The Durbin-Watson value (1.997936) suggests that there is no treat of serial correlation in the model.

Table 4. Below presents the long run effect of disease burden on wealth creation

\begin{tabular}{ccccc}
\hline Variable & Coefficient & Std. Error & t-Statistic & Prob. \\
\hline C & 19.56324 & 2.257946 & 8.664173 & 0.0001 \\
LOGEDB & 0.085163 & 0.058411 & 1.457981 & 0.1951 \\
LOGTIS & -0.008285 & 0.107414 & -0.077127 & 0.9410 \\
LOGLEB & -12.04173 & 2.868978 & -4.197218 & 0.0057 \\
LOGPRR & 0.077157 & 0.100665 & 0.766471 & 0.4725 \\
LOGPOP & 0.786394 & 0.780998 & 1.006910 & 0.3528 \\
R-squared & 0.998617 & Mean dependent var & 5.094796 \\
Adjusted R-squared & 0.997464 & S.D. dependent var & 0.071822 \\
S.E. of regression & 0.003617 & Akaike info criterion & -8.099483 \\
Sum squared resid & $7.85 \mathrm{E}-05$ & Schwarz criterion & -7.857029 \\
Log likelihood & 54.59690 & Hannan-Quinn criter. & -8.189248 \\
F-statistic & 866.2432 & Durbin-Watson stat & 1.747624 \\
Prob (F-statistic) & 0.000000 & & \\
\hline
\end{tabular}

Source: Authors' Computation (2020) using E-Views 9

In the long run, trade in services which was used to captured wealth creation and life expectancy at birth was able to maintain their respective apriori signs. Which means in the long run, wealth creation has the tendency of reducing the disease burden in Nigeria. Even though the reduction is not statistically significant but with increasing in life expectancy rate at birth, the disease burden will be reduced statistically. The ease of doing business was also a variable taken to ascertain its effects on disease burden. This variable was not able to maintain its apriori sign. A percentage increase in ease of doing business will increase disease burden by $0.9 \%$. The reason being simply was that the necessary modalities needed in Nigeria to make business thrive such as social amenities and political stability is lacking and or inadequate.

The goodness of fit is highly commendable even after the degrees of freedom it was still able to maintain high 
predictive ability of $0.99 \%$, which means the model was able to capture 99 per cent predictive variation between the dependent and independent variables. Only 1 per cent is attributed to chance.

The Durbin Watson statistic of 1.75 shows the absent of serial correlation among the variables, and the F-statistic of 866.243 shows that the variables fits in well in the model which is statistically significant (Table 4).

Table 5. Below presents the long run effect of wealth creation on disease burden

\begin{tabular}{|c|c|c|c|c|}
\hline Variables & Coefficients & Std. Error & t-statistics & Prob. \\
\hline $\mathrm{C}$ & -54.12066 & 27.34038 & -1.979514 & 0.0951 \\
\hline LOGDB & 0.017442 & 0.014492 & 1.203600 & 0.2741 \\
\hline LOGPOP & -1.834549 & 7.012604 & -0.261607 & 0.8024 \\
\hline LOGLEB & 38.88151 & 43.00999 & 0.904011 & 0.4008 \\
\hline LOGPRR & -0.372288 & 0.639049 & -0.582565 & 0.5814 \\
\hline LOGTIS & -0.296426 & 0.663071 & -0.447050 & 0.6705 \\
\hline \multicolumn{5}{|c|}{ R-squared 0.960109} \\
\hline \multicolumn{5}{|c|}{ Adjusted R-squared 0.926867} \\
\hline \multicolumn{5}{|c|}{ F-statistic 28.88222} \\
\hline \multicolumn{5}{|c|}{ Prob. (F-statistic) 0.000398} \\
\hline \multicolumn{5}{|c|}{ Durbin-Watson stat 2.080786} \\
\hline
\end{tabular}

Note: $* * * * *$ and $*$ indicate significance at $1 \%, 5 \%$ and $10 \%$ level respectively. $\mathrm{C}$ is the constant variables which is automatically generated by the Econometric Views (E-Views) softwares.

Source: Authors' Computation (2020) using E-Views 9

Table 6. Granger causality result

\begin{tabular}{cccc}
\hline Null Hypotheses & Lags & F-Statistic & Prob. \\
\hline LOGTIS does not Granger Cause LOGDB & 1 & 0.31546 & 0.5796 \\
LOGDB does not Granger Cause LOGTIS & 1 & 1.38874 & 0.2502 \\
LOGTIS does not Granger Cause LOGDB & 2 & 4.68304 & 0.0208 \\
LOGDB does not Granger Cause LOGTIS & 2 & 0.81832 & 0.4548 \\
LOGTIS does not Granger Cause LOGDB & 3 & 2.77126 & 0.0714 \\
LOGDB does not Granger Cause LOGTIS & 3 & 1.10509 & 0.3728 \\
LOGPOP does not Granger Cause LOGDB & 1 & 4.58965 & 0.0425 \\
LOGDB does not Granger Cause LOGPOP & 1 & 8.67898 & 0.0071 \\
LOGPOP does not Granger Cause LOGDB & 2 & 1.86813 & 0.1792 \\
LOGDB does not Granger Cause LOGPOP & 2 & 1.12873 & 0.3423 \\
\hline
\end{tabular}

Source: Authors' Computation (2020) using E-Views 9

From Table 5, The model was still able to capture 96 per cent variation between the dependent variable and independent variables. Even after taking the degrees of freedom the predictive ability is still very high which is 93 per cent and only 7 per cent is left to chance. Durbin Watson statistics shows that there is no trace of serial correlation which 
means that the model is ok with best predictive ability which is highly significant at even 1 per cent level.

Table 6 displays the Granger causality result. It shows that we fail to accept the null hypothesis of no directional relationship or causality between disease burden and wealth creation in Nigeria. This implies that wealth creation does not necessarily lead to disease burden but the converse may hold as the disease burden granger cause wealth creation.

An attempt was also made to see whether there is granger causality between disease burden and the population rate. The empirical evidence shows that we fail to reject the null hypothesis of no directional relationship between disease burden and population incidence in Nigeria and the converse also holds, which means that there is a bidirectional relationship between disease burden and population rate in Nigeria.

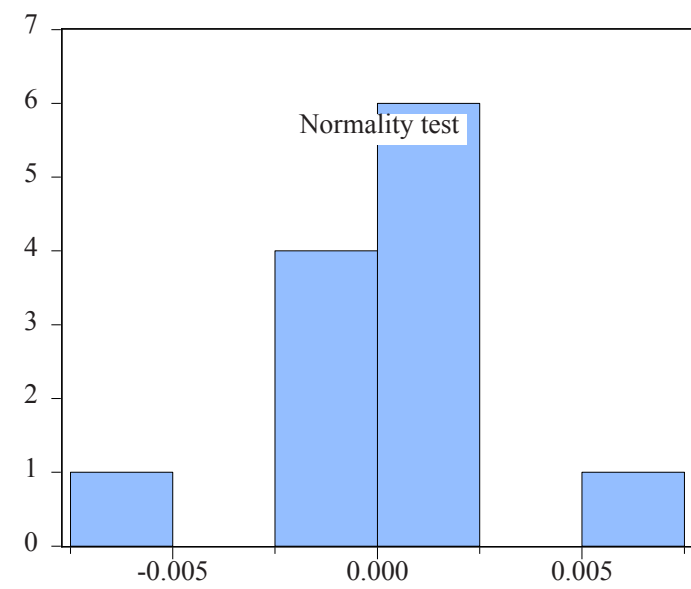

Series: Residuals

Sample 20062017

Observations 12

Mean $\quad 5.03 \mathrm{e}-15$

Median $\quad 0.000444$

Maximum $\quad 0.005159$

Minimum $\quad-0.005487$

Std. Dev. $\quad 0.002671$

Skewness $\quad-0.179835$

Kurtosis $\quad 3.320598$

Jarque-Bera $\quad 0.116073$

Probability 0.943615

Figure 1. Above is the normality test which shows the descriptive statistic This is computed by the authors' from the data WDI (2020) using E-views 9.

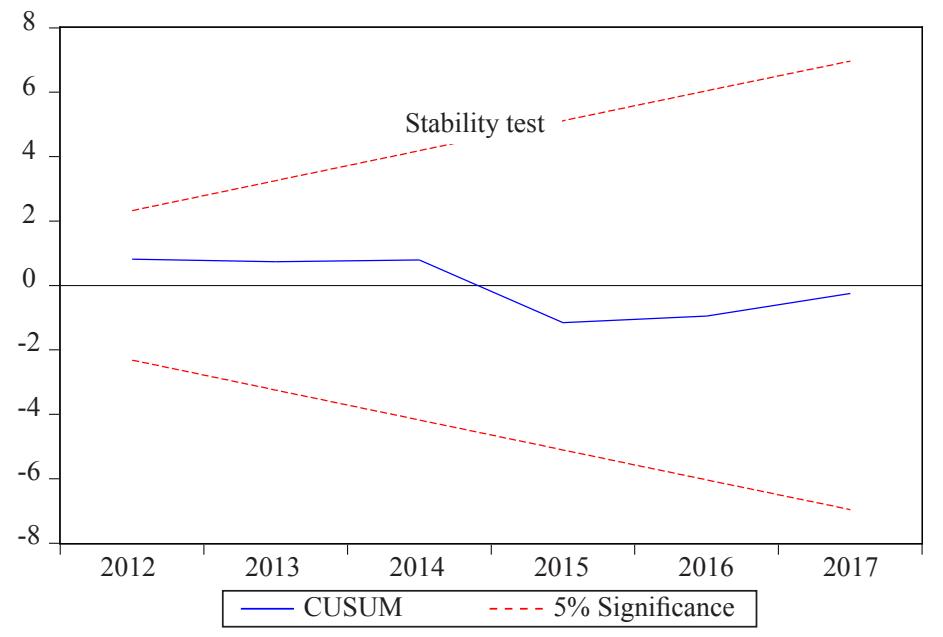

Figure 2. Cumulative sum test

Figure 1 shows Normality test also known as descriptive statistics. Figure 2 shows the stability test graph. It measures the stability of the distribution or how stable is the distribution over time to avoid erroneous conclusion which may lead to wrong policy recommendation when the variables are not stable.

Cumulative sum test is the figure above is the stability test of the distribution which aims at showing whether the 
distribution is stable over time or not. But from the blue line of Cumulative Sum (CUSUM), we can conclude that the variables are stable over time.

Cumulative sum of square test is the figure above is the measure of the stability test of the variables over time. Both sum of squares and cumulative sum of squares are both used for stability test. This shows that the variables are normally distributed over time. This is shown by the blue line on both Figure 2 and Figure 3 of both CUSUM and CUSUM of squares respectively. The cumulative sum and sum of squares both fall within the acceptance region of $5 \%$ level of significance showing stability of the variables over time at $95 \%$ confidence level and only $5 \%$ is attributed to chance.

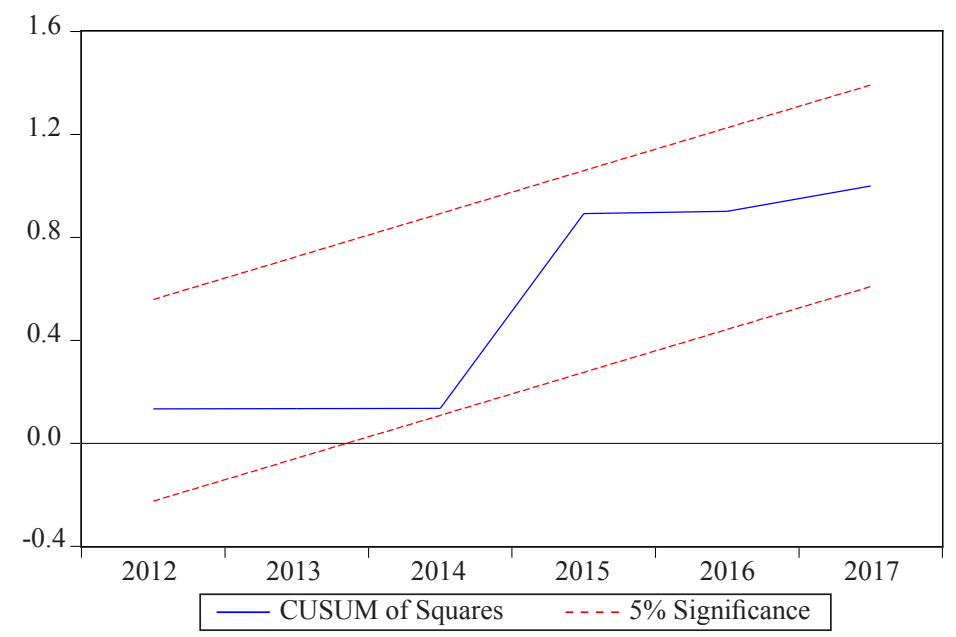

Figure 3. The cumulative sums of squares

\section{Conclusion and recommendation}

The main objective of this study was to empirically examine the impact of disease burden on wealth creation using annual time series data spanning from 2006 to 2018. Based on the empirical findings, we can lucidly draw the following conclusion that wealth creation has a significant impact on disease burden in Nigeria. This can conversely suggest that as source of livelihood increase, the disease burden on the population is reduced because people will have income that will be a magnet for health consideration which invariably will reduce the chances of suffering from diseases. The life expectancy at birth has more impact on disease burden than population and even wealth creation. The empirical evidence shows that a percentage increase in life expectancy at birth, the disease burden will reduce to about $12.1 \%$. This conforms to the apriori expectation which shows that the life expectancy at birth is expected to reduce the disease burden, as such the reason for the inverse relationship. All the necessary precursors needed to put in place to boost life expectancy at birth should be harnessed. The population of Nigeria also has shock on disease burden in Nigeria. From the empirical evidence, as the population increase, the burden of diseases in Nigeria is also heightened. This means that the population outburst is causing more pressure on the disease burden in Nigeria.

Based on the empirical evidences and the conclusions drawn, it is recommended that all measures that are needed to be taken by both government and nongovernmental organizations to increase the income and wealth of the citizens should be taken. These measures include investing in education, providing incentives to businesses, creating a business friendly environment, and bridging the infrastructural gap. Fighting poverty through wealth creation is invariably fighting the burden of diseases in Nigeria. Thus, the fight should not be taken lightly.

Population control measures should be put in place. There should be a decree/law that will state the number of children a woman is expected to have and the time lag of having them. By so doing, the life expectancy at birth will be increased, infant mortality will be reduced and the chances of women getting infectious disease will also be reduced. And when this happens, the time women spent in nursing their children will be lessened as they would have few children to cater for which invariably will increase labour productivity and their productive time in wealth creation. 


\section{Conflict of Interest}

The authors agree that there is no disagreement, conflicting of interest or personal interest among the authors in regards to this paper.

\section{References}

Dading, F. I., \& kanwanye, H. T. (2019). Impact of malaria on maternal mortality in Nigeria. Dutse Journal of Economics and Development Studies (DUJEDS), 8(1), 2536-6130.

Defo, B. K. (2014). Demographic, epidemiological, and health transitions: Are they relevant to population health patterns in Africa? Global Health Action, 7(1), 22443. https://doi.org/10.3402/gha.v7.22443

Engle, R. F., \& Granger, C. W. J. (1987). Co-integration and error correction: Representation, estimation, and testing. Econometrica, 55(2), 251-276.

Granger, C. W. J., \& Newbold, P. (1974). Spurious regressions in econometrics. Journal of Econometrics, 2(2), 111-120.

Grossman, M. (1972). The demand for health: A theoretical and empirical investigation. New York: Columbia University Press.

Dickey, D. A., \& Fuller, W. A. (1979). Distribution of the estimate for autoregressive time series with a unit root. Journal of the American Statistical Association, 79, 427-431.

Hansen, C. W., \& Strulik, H. (2015). Life expectancy and education: Evidence from the cardiovascular revolution. Journal of Economic Growth, 22, 421-450.

Iyoha, M. A. (2004). Applied econometrics (2nd ed.). Benin City: Mindex Publisher.

Lajoie, J. (2015). Understanding the measurement of global burden of disease. National Collaborating Centre for Infectious Diseases.

Lopez, A. D., Mathers, C. D., Ezzati, M., Jamison, D. T., \& Murray, C. J. L. (2006). Measuring the global burden of disease and risk factors, 1990-2001. Global Burden of Disease and Risk Factors. Washington (DC): The International Bank for Reconstruction and Development, The World Bank; New York: Oxford University Press.

Maigemu, A. Y., \& Hassan, K. H. (2015). Malaria as a cause of morbidity and mortality: A socio-economic overview. Research on Humanities and Social Sciences, 5(8), 100-105.

Mojekwu, J. N., \& Ibekwe, U. (2012). Maternal mortality in Nigeria: Examination of intervention methods. International Journal of Humanities and Social Science, 2(20), 135-149.

Morand, O. F. (2002). Economic growth, longevity, and the epidemiological transition. Economics Working Papers.

Murray, C. J. L. (1996). Rethinking DALYs in the global burden of disease. Cambridge, MA: Harvard University Press.

Murray, C. J. L., D. Phil, M. D., \& Lopez, A. D. (2013). Measuring the global burden of disease. The New England Journal of Medicine, 369(5), 448-457.

Nigeria Malaria Indicator Survey. (2015). National Malaria Elimination Programme (NMEP), National Population Commission (NPopC), National Bureau of Statistics (NBS). Abuja, Nigeria, and Rockville, Maryland, USA: NMEP, NPopC, and ICF International.

Nwanosike, D. U., Ikpeze, I. N., \& Ugbor, I. K. (2015). Investigation of malaria prevalence and health outcome in Nigeria. Journal of Humanities and Social Science, 20(5), 79-84.

Omran, A. R. (1971). The epidemiologic transition: A theory of the epidemiology of population change. Milbank Memorial Fund Quarterly, 49(1), 509-538.

Omran, A. R. (1982). Epidemiologic transition. In John A. Ross (Ed.), International Encyclopedia of Population (pp.175-183). The Free Press.

Van Zon, A., \& Muysken, J. (2001). Health and endogenous growth. Journal of Health Economics, 20(2), $169-185$.

WHO. (1990). World Health Organization Stud Group. "Diet” Nutrition and the Prevention of Chronic Diseases. WHO Technical Report 1990 series 799.

WHO. (2008). The global burden of disease: 2004 update. World Health Organization, Geneva.

WHO. (2020). Cardiovascular diseases. World Health Organization, Geneva. https://en.wikipedia.org/wiki/Disease_ burden

World Development Indicators (2020). World Bank, Data Bank.

World Development Indicators. (2019). The World Bank Group, Data Bank. 